\title{
Isolated renal hydatid cyst misdiagnosed and treated as a cystic renal tumor: a diagnostic pitfall
}

\author{
Moez Hamdani* (D), Ahlem Bdioui, Oussama Belkacem, Nizar Jelidi, Atika Baccouche, Wiem Majdoub and \\ Sihem Hmissa Belhaj Salah
}

\begin{abstract}
Background: The hydatid disease is a parasitic infestation caused by the larval stage of Echinococcus granulosus. The renal location of this infectious disease is uncommon compared to hepatic or pulmonary ones. Most patients remain asymptomatic for years and hydatiduria is the only pathognomonic clinical symptom. We report a rare case of renal hydatid cyst misdiagnosed and treated as a renal tumor.

Case presentation: A 45-year-old woman with no significant medical or surgical history presented with left lumber pain with hematuria. Magnetic Resonance Imaging (MRI) displayed a left renal mass with cystic and solid components, showing discreet enhancement, classified as Bosniak IV. The diagnosis of renal malignant tumor was made. The patient underwent a lumbotomy. Intraoperatively, the mass was adherent to the perirenal fat and seemed to invade the adrenal gland. An enlarged left nephrectomy with surrenalectomy was performed. The gross specimen showed a superior polar renal cyst $(9 \times 7 \times 6 \mathrm{~cm})$. The cyst had a thick wall and contained multiple internal smaller cysts recalling the appearance of the hydatid cyst. The microscopic study showed a cyst wall consisting of acellular eosinophilic laminated membrane lined by a thin germinal layer from which merge daughter cysts. This cyst wall is surrounded by a dense fibrovascular tissue with chronic inflammatory cells. The diagnosis of renal hydatic cyst was made.
\end{abstract}

Conclusion: Although the renal hydatid cyst is relatively rare, this diagnosis must be considered in patients with renal cystic masses, especially endemic countries. Preoperative diagnosis is challenging, especially in type IV cysts which can mimic a renal tumor and lead to overtreatment.

Keywords: Hydatid cyst, Echinococcus granulosus infection, Nephrectomy, Misdiagnosis, Case report

\section{Background}

The hydatid disease is a parasitic infestation caused by the larval stage of Echinococcus granulosus. Humans are accidental intermediate hosts infected indirectly through ingestion of parasite eggs in contaminated food, water or soil, or through direct contact with animal hosts [1, 2]. The kidney is an uncommon site of the hydatid cyst compared to hepatic or pulmonary ones $[1,3]$. Isolated presentation of renal hydatid cyst (RHC) is extremely rare and it may be misdiagnosed as a renal tumor $[1$, 4]. Most patients remain asymptomatic for years and hydatiduria is the only pathognomonic clinical symptom. Although the majority of renal masses are malignant, the diagnosis of isolated RHC should be kept in mind especially in endemic countries.

Hereby, we report a rare case of an isolated renal hydatid cyst misdiagnosed and treated as a renal tumor.

*Correspondence: moez.hamdani@gmail.com

Department of Pathology, Sahloul University Hospital of Sousse,

4011 Hammam Sousse, Tunisia 


\section{Case presentation}

A 45-year-old woman with no significant medical or surgical history, presented with hematuria for one month. The medical questionnaire revealed a left lumber intermittent pain during the past four years. Physical examination showed left flank tenderness. Routine blood tests were within normal limits. Magnetic Resonance Imaging (MRI) displayed a left renal mass of $8 \times 7 \times 6 \mathrm{~cm}$ with cystic and solid components. The solid components showed discreet enhancement after the injection of Gadolinium (Fig. 1). The mass was classified as Bosniak IV. There was no renal hilar lymphadenopathy. Both left renal vein nor and vena cava were free of thrombosis. The diagnosis of renal malignant tumor was suspected.

The patient underwent a left lumbotomy. The renal mass was adherent to the perirenal fat and seemed to invade the adrenal gland. An enlarged left nephrectomy as well as a surrenalectomy were then performed. The postoperative period was uneventful.

The gross specimen showed a superior polar renal cyst measuring $9 \times 7 \times 6 \mathrm{~cm}$. The cyst had a thick wall and contained multiple internal smaller cysts recalling the appearance of the hydatid cyst (Fig. 2). The microscopic study showed a cyst wall consisting of acellular eosinophilic laminated membrane lined by a thin germinal layer from which merge daughter cysts. The cyst wall is surrounded by a dense fibrovascular tissue with chronic inflammatory cells (Fig. 3). This typical histological presentation led to the diagnosis of RHC. After a 6-month follow up period, the patient was asymptomatic and doing well.

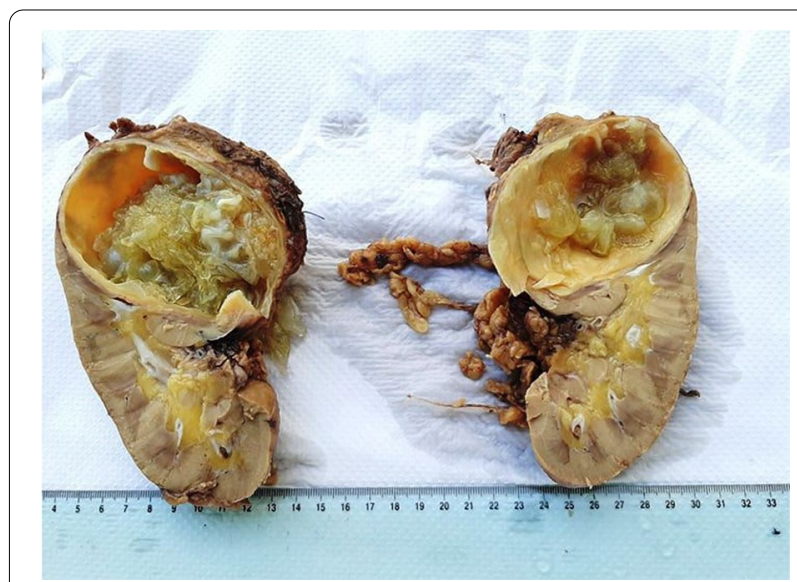

Fig. 2 Macroscopic findings: renal cyst $(9 \times 7 \times 6 \mathrm{~cm})$ containing multiple internal smaller cysts recalling the appearance of the hydatid cyst

\section{Discussion}

The hydatid disease rarely affects kidneys. The renal site represents 2 to $4 \%$ of all localizations $[1,3,5]$. Few cases of RHC were reported [5-7]. Echinococcal larvae may reach the kidneys through the blood stream, lymphatics or by direct inoculation $[5,6]$.

There are no specific symptoms for RHC. It usually remains asymptomatic for years. Hydaturia, which is the presence in urine of gelatinous material and membranes reminding grape skins in texture, is pathognomonic of ruptured RHC in the renal collecting system [7].

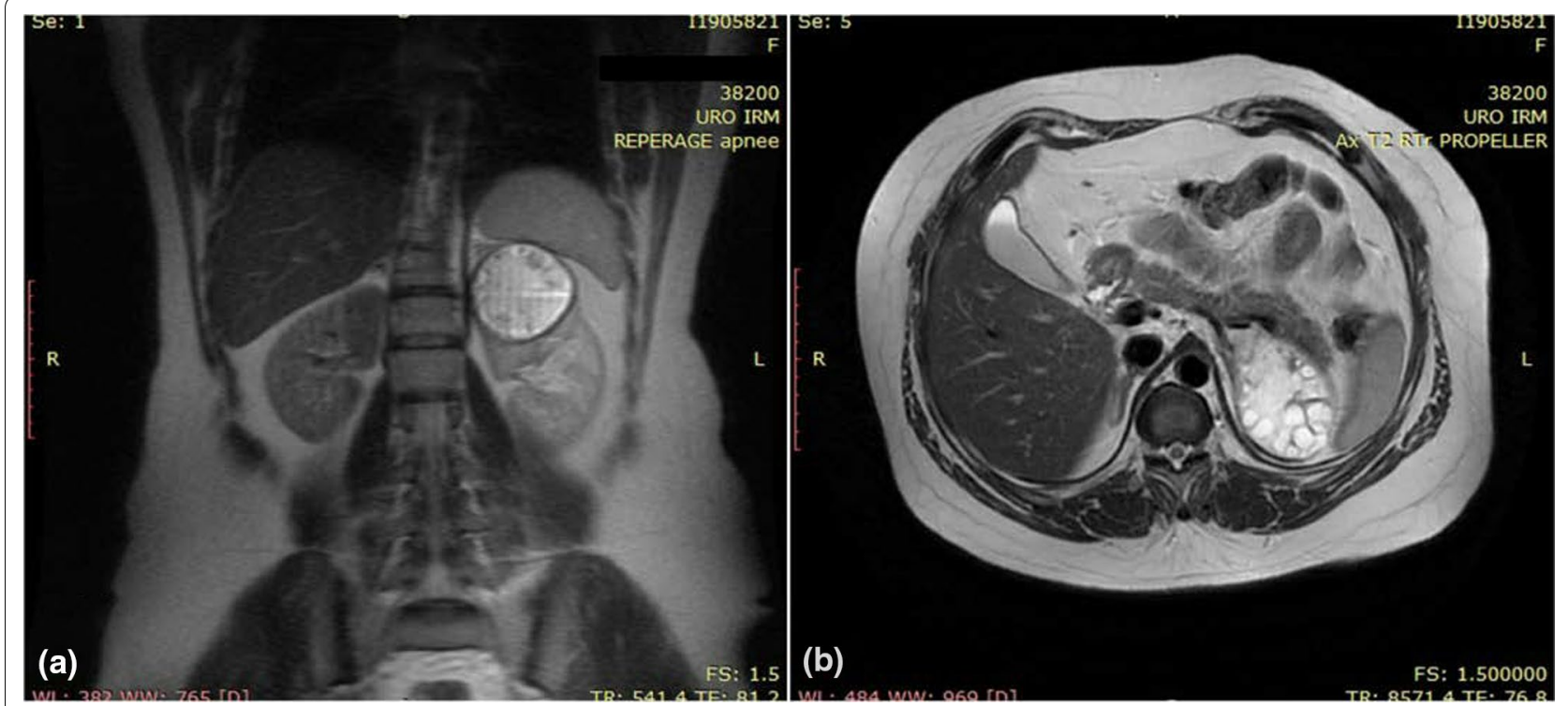

Fig. 1 MRI findings: a left renal mass with cystic and solid components, showing discreet enhancement classified as Bosniak-IV 


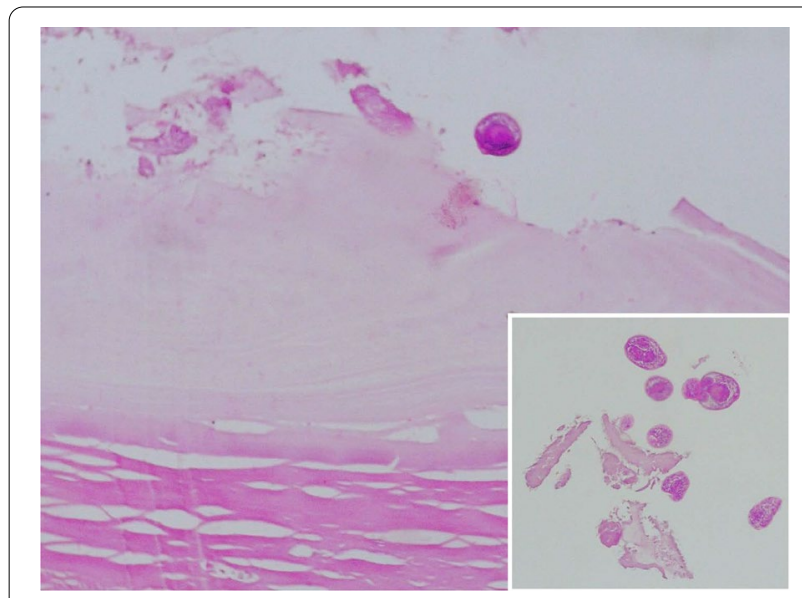

Fig. 3 Histology $(H E \times 40)$ : acellular eosinophilic laminated membrane lined by a germinal layer with daughter cysts

Serology could be useful in the diagnosis of hydatid disease. However, the rates of false negative results are high [2]. Diagnosis of renal hydatid cyst is based mainly on imaging [2]. Ultrasound is the most essential tool for hydatid disease. This technic clearly demonstrates the floating membranes, daughter cysts, and hydatid sand characteristically seen in purely cystic lesions [2]. The CT-scan represents the 2nd line examination, especially for the diagnosis of complex renal cysts [8]. When CT-scan cannot be used (e.g.: altered renal function), magnetic resonance imaging (MRI) is performed [8]. Although our patient had a normal renal function, we opted for an MRI. In fact, this technic is not less performant than CT-scan in the majority of cystic renal masses [9].

Although isolated RHC is rare, it should be taken into consideration in the differential diagnosis of renal cystic masses, especially in endemic countries. Despite advancements in imaging technics, preoperative diagnosis is challenging, especially in type IV cysts, which can mimic a renal tumor and lead to overtreatment [4].

The treatment of RHC is surgical. Conservative renal surgery is possible even for large lesions [3]. Aspiration followed by controlled evacuation of the cyst could facilitate the removal of the membrane. This will allow a safe management of the surgery with less mortality and morbidity [3]. Excision of the cyst with surrounded tissues is a very common technic performed regardless the size of the cyst [3]. Recently, percutaneous drainage and alcohol instillation have also been described as safe and minimally invasive therapeutic options in selected cases [10]. In the present case, the attitude was radical. Since benign kidney tumor are very rare, any kidney tumor should be considered as malignant. Furthermore, the well-defined character in the MRI is not necessarily reassuring since some kidney cancers are well limited. However, in this case, a preoperative diagnosis of the RHC, would have allowed conservative surgery.

\section{Conclusion}

Although isolated RHC is rare, it should be considered in the differential diagnosis of renal cystic masses, especially in endemic countries. Despite advancements in imaging technics, preoperative diagnosis is challenging. Indeed, type IV cysts may mimic a renal tumor. Therefore, an accurate preoperative diagnosis of RHC is required to avoid overtreatment.

\section{Abbreviations}

MRI: Magnetic resonance imaging; RHC: Renal hydatid cyst.

\section{Acknowledgements}

We thank Dr Ichraf Anane for proofreading and precious help. The abstract mentioned is of authors' E-poster entitled "Renal hydatid cyst misdiagnosed and treated as a cystic renal tumour: a diagnostic pitfall" presented during the 32 nd Congress of the ESP and XXXIII International Congress of the IAP (December 2020).

\section{Authors' contributions}

$\mathrm{MH}, \mathrm{OB}, \mathrm{NJ}, \mathrm{AB}, \mathrm{WM}, \mathrm{ABe}$, SHBS were involved in substantial contributions to conception of the case report and acquisition of data. MH was involved in substantial contributions to literature search. $\mathrm{MH}$ was involved in substantial contribution to writing of the paper manuscript with revision. SHBS was involved in substantial contributions to critical revision. All authors have read and approved the final version of the manuscript.

\section{Funding}

None.

Availability of data and materials

The data used in the current study are with the corresponding author and are available on reasonable request.

\section{Declarations}

Ethics approval and consent to participate

Not applicable (Approval from an institutional board review is not required for a case report)

\section{Consent for publication}

Written informed consent had been taken from the patient for publication of this case report and corresponding images.

\section{Competing interests}

The authors declare that they have no competing interests.

Received: 30 December 2020 Accepted: 21 May 2021

Published online: 31 May 2021

\section{References}

1. Ghandour R, Nassar G, Hejase MJ (2020) Renal Echinococcosis mistaken for a cystic renal tumor: a case report. Urology Case Rep 1(28):101030

2. Rexiati M, Mutalifu A, Azhati B, Wang W, Yang H, Sheyhedin I et al (2014) Diagnosis and surgical treatment of renal hydatid disease: a retrospective analysis of 30 cases. PLoS ONE 9(5):e96602 
3. Zmerli S, Ayed M, Horchani A, Chami I, El Ouakdi M, Ben Slama MR (2001) Hydatid cyst of the kidney: diagnosis and treatment. World J Surg 25(1):68-74

4. Gadelkareem RA, Elqady AA, Abd-Elshafy SK, Imam H, Abolella HA (2018) Isolated renal hydatid cyst misdiagnosed and operated as a cystic renal tumor. Med Princ Pract 27(3):297-300

5. Göğüș C, Safak M, Baltaci S, Türkölmez K (2003) Isolated renal hydatidosis: experience with 20 cases. J Urol 169(1):186-189

6. Aragona F, Di Candio G, Serretta V, Fiorentini L (1984) Renal hydatid disease: report of 9 cases and discussion of urologic diagnostic procedures. Urol Radiol 6(1):182-186

7. Horchani A, Nouira Y, Kbaier I, Attyaoui F, Zribi AS (2000) Hydatid cyst of the kidney. Eur Urol 38(4):461-467
8. Sountoulides P, Zachos I, Efremidis S, Pantazakos A, Podimatas T (2006) Nephrectomy for benign disease? A case of isolated renal echinococcosis. Int J Urol 13(2):174-176

9. Agnello F, Albano D, Micci G, Di Buono G, Agrusa A, Salvaggio G et al (2020) CT and MR imaging of cystic renal lesions. Insights Imaging 11(1):5

10. Israel GM, Hindman N, Bosniak MA (2004) Evaluation of cystic renal masses: comparison of CT and MR imaging by using the Bosniak classification system. Radiology 231(2):365-371

\section{Publisher's Note}

Springer Nature remains neutral with regard to jurisdictional claims in published maps and institutional affiliations.

\section{Submit your manuscript to a SpringerOpen ${ }^{\circ}$ journal and benefit from:}

- Convenient online submission

- Rigorous peer review

- Open access: articles freely available online

- High visibility within the field

- Retaining the copyright to your article

Submit your next manuscript at $\gg$ springeropen.com 